\title{
Granuloma Annulare
}

National Cancer Institute

\section{Source}

National Cancer Institute. Granuloma Annulare. NCI Thesaurus. Code C3470.

A localized or generalized inflammatory skin disorder characterized by the formation of papules and ring-shaped plaques in the skin. Morphologically these lesions are granulomatous inflammatory processes with central necrosis surrounded by palisading histiocytes. 